\title{
CORRELATES OF NON-ADHERENCE TO HOME EXERCISE PROGRAMMES IN PATIENTS WITH LOW BACK PAIN
}

\author{
Odebiyi Do ${ }^{1}$, Fapojuwo Oa ${ }^{* 2}$, Olaleye Bf ${ }^{1}$, Olaniyan $\mathrm{As}^{2}$ \\ ${ }^{1}$ Departments of Physiotherapy, Faculty of Clinical Sciences, College of Medicine, University of \\ Lagos, Lagos, Nigeria \\ 2 Departments of Physiotherapy, Lagos University Teaching Hospital, Lagos, Nigeria
}

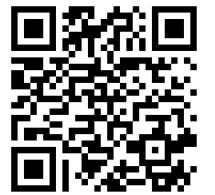

DOI: https://doi.org/10.29121/granthaalayah.v8.i6.2020.443

Article Type: Research Article

Article Citation: Odebiyi Do, Fapojuwo Oa, Olaleye Bf, and Olaniyan As. (2020). CORRELATES OF NON-ADHERENCE TO HOME EXERCISE PROGRAMMES IN PATIENTS WITH LOW BACK PAIN. International Journal of Research GRANTHAALAYAH, 8(6), 280-292. https://doi.org/10.29121/granthaa layah.v8.i6.2020.443

Received Date: 08 April 2020

Accepted Date: 30 June 2020

Keywords:

Non-Adherence to Exercise Program Relationship

Low Back Pain

\section{ABSTRACT}

Background: Non-adherence to home exercise programmes may lead to delayed progress in recovery and diminished clinical outcomes in patients.

Aims of Study: To determine the adherence rate and attributing factors to non-adherence to home exercise programmes in patients with low back pain (LBP).

Method: A total of 250 patients with LBP receiving treatment in 5 different out-patient physiotherapy clinics in Lagos State South West, Nigeria participated in this survey. They were required to complete a 27item questionnaire which collected information on characteristics of participants and home exercise programme, adherence with treatment programme and instructions for carrying out the exercises. Gamma correlation and Chi-square were used to detect the correlation and significant difference of selected variables respectively. The level of significance was set at $\mathrm{p}<0.05$

Result: Ninety-four (37.6\%) respondents performed home exercise programme the recommended number of times daily. There was no significant relationship ( $p>0.05$ ) of participants' characteristics, frequency and duration of exercise per session, total number and manner of recommending the home exercise programme and pain rating respectively with adherence to home exercise programme. Eighty-nine (35.6\%) respondents complained of tiredness after the day's work. Chi-square showed significant association $(p<0.05)$ of the prescribed home exercises programme, the actual exercise carried out at home with their perception to home exercise programme

Conclusion: Home exercise programmes may interfere with normal life and daily routine in patients with LBP. It is recommended that home exercise programme be patient centred I.e. fit into individual daily routine to overcome identified barriers.

\section{INTRODUCTION}

Low back pain (LBP) is responsible for huge personal and societal costs, and is major cause of work disability (Moffett and McLean, 2006). Epidemiological reviews suggest that it is rising among Africans and therefore a concern

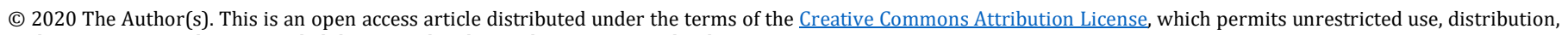
and reproduction in any medium, provided the original author and source are credited. 
for healthcare professionals (Louw et al, 2007). Systematic reviews also provides evidence of the benefits of exercise in effectively decreasing pain and improving function in Low Back Pain patients (Sarig-Bahat, 2003; Hayden et al, 2005; Kay et al, 2005).

Home exercise programmes are often instructed individually and prescribed by physiotherapists to be performed at home by the patients (Pilar Escolar-Reina et al, 2010).For an exercise regimen to be successful, the patient must have the knowledge and skill to perform the regimen as well as an intention to do so (PeterandNick, 2004). Although home-based exercises vary greatly in the methods of delivery and content (Moffet et al, 2006), different programmes appear to have similar effects on patients (Slade and Keating, 2006; 2007).

Scientific evidence suggests that inadequate adherence to home-based exercises may attenuate the treatment's efficacy (Hayden et al, 2005; Kolt and McEvoy, 2003). Also many recurrent cases of LBP could have been avoided if patients had adhered to their home exercise programmes (Middleton, 2004). It has been reported that adherence to exercise is often a serious issue for patients with LBP (Slade and Keating, 2006; 2007). Most home programmes for LBP are prescribed by physiotherapists (Poitras et al, 2005).

A problem frequently faced by physiotherapists is that patients may fail to recover from their injury in spite of the fact that there is no apparent pathological basis for this poor outcome (Bassett, 2003). This may mislead physiotherapists to wrongly think the treatment programme is not fulfilling the needs of the patients, a decision that is based solely on their physical status (Bassett, 2003). However, had the patients' psychological and behavioral responses to their injury and treatment been taken into account then it is possible poor treatment adherence might have been detected. Poor adherence to physiotherapy is a problem with up to $65 \%$ of patients being either non adherent or partially adherent to their home programmes, and approximately $10 \%$ of patients failing to complete their prescribed course of physiotherapy (Basset, 2003). Non-compliance to exercise regimen is a major obstacle to the effective delivery of health care. Estimates from the (WHO, 2003) indicate that only about $50 \%$ of patients with chronic diseases living in developed countries follow treatment recommendations which put health at risk (APA Highlights Newsletter, 2004). In particular, low rates of adherence to therapies for asthma, diabetes, and hypertension are thought to contribute substantially to the human and economic burden of those conditions (Harris, 2010). Compliance rates may be overestimated in the medical literature, as compliance is often high in the setting of a formal clinical trial but drops off in a "real-world" setting. Several systematic reviews provide evidence of the benefits of exercise among people with chronic back pain (WHO, 2003).

Therefore, patient's adherence is of considerable importance to physical therapy because treatment outcome partly depends on it. The efficacy of physical exercises can only be established when patients comply with the exercise regimen (Sluijs et al, 1993). Hence, this study was designed to evaluate the predictive factors of adherence to frequency and duration of home exercise programme in low back pain.

\section{METHODS}

A cross - sectional descriptive survey was carried out on patients with low back pain who were receiving treatment in out-patient physiotherapy clinics from three selected hospitals in Lagos, South West Nigeria. The hospitals are Lagos University Teaching Hospital, National Orthopaedic hospital, Lagos State University Teaching Hospital, General Hospital Marina, General Hospital Gbagada and Federal Medical Centre Ebute- Metta. Ethical approval was sought and obtained from the Committee on Research and Ethics of the College of Medicine Lagos University Teaching Hospital, Idi-Araba Lagos, Nigeria. All the respondents gave their informed consent. Subjects with low back pain of mechanical origin who had been receiving physiotherapy treatment for low back pain for at least one month after intervention were included in the survey. Patients younger than 18 years or older than 80 years, patients with cognitive deficit, co - morbid conditions, patients who were unable to attend all treatment sessions of physiotherapy, and patients who stopped home exercise programme by physiotherapist's prescription were excluded from the study.

\subsection{QUESTIONNAIRE DESIGN}

A 27-item self-administered questionnaire titled "Predictive Factors of Adherence to Home Exercise Programme" (PFA- HEP) Questionnaire was employed as the survey instrument. The initial draft of the questionnaire was adopted from previous related studies (Chappell and Williams 2002; Medina- Mirapeix et al 2009) 
and served as the working document for development of the final draft by a four man focus group. Prior to distribution, the questionnaire was sent to two physiotherapy educators in the College of Medicine, University of Lagos who are experts in questionnaire design to determine the content validity.

The questionnaire had five sections. Section A sought information on demographic data such as age, gender, education level, work participation, sick leave or off work. Section B collected information on previous physiotherapy treatment, home exercise programmes in the previous treatment, numerical pain rating scale, extent of limitation due to pain, type of exercise given, total number of exercise given, the agreed number of days to perform the HEP, times per week, how long per session and how many times or repetitions per session. Section $\mathrm{C}$ was on compliance from the patients patient's point of view and sought to elicit information about the agreed number of HEP given, extent at which the patients adhered to HEP, reasons for missing HEP, extent at which HEP had affected the patientphysiotherapist behaviour in clinical encounters such as clarity of doubts, information about illness and usefulness of the advice. Section Dgleaned data on way home HEP was given, level of clinical supervision of the exercises, follow - up received and extent of review of the HEP. The questionnaires were distributed and given to each respondent individually by the researcher (OBF) by personal visitation to all the hospitals involved in the study.

\section{DATA ANALYSIS}

Data were summarized using descriptive statistics of frequencies and percentages. Gamma correlation was used to detect the correlation between ordinal variables and Chi-Square was used to determine the association between other selected variables. Data collected were analyzed using the SPSS version 17 (SPSS Inc., Chicago, Illinois, USA). The alpha level was set at 0.05 .

\section{RESULTS}

\subsection{CHARACTERISTICS OF PATIENTS}

A total of 250 copies of the questionnaires were distributed and all were returned and completed satisfactorily, giving a response rate of $100 \%$. The descriptive information of all respondents is presented in table 1 . Females and males accounted for $64 \%$ and $35.6 \%$ of the sample population respectively., The mean age of the subjects was $58.2 \pm 9.5$ years with majority $126(51 \%)$ above 59 years. Fewer number of respondents $33(13.2 \%)$ were off work or on sick leave at the time of the study (Table1). Majority of respondents $181(72.4 \%)$ had no contact with physiotherapy treatment prior to present episode of LBP (Table 1). Ninety-six $(38.40 \%)$ of the respondents had tertiary education and $129(51.60 \%)$ were in paid employment. However, there was no significant relationship of the level of adherence to HEP with the highest educational attainment $(\mathrm{C}=0.01 ; \mathrm{p}=0.80)$ and the employment status of the respondents $(\mathrm{C}=0.00 ; \mathrm{p}=0.99)$ (Table 2).Two hundred and ten $(84 \%)$ of respondents were not given home exercise programme in previous episodes of physiotherapy treatment (Table 2). However, there was no significant relationship between prescription of HEP in previous episodes of pain and the level of adherence to HEP $(\mathrm{C}=-0.03$; $\mathrm{p}=0.81$ ) (Table 2).

\subsection{CHARACTERISTICS OF HOME EXERCISE PROGRAMME}

Respondents were prescribed different types of HEP, with the majority 86(34.4\%) given modified press- up (Table 3). Most of respondents,218(87.2\%) do HEP every day of the week (Table 4). The total number of exercise given to respondents were grouped into three with the majority $242(98.8 \%)$ given 1-3 exercises (Table 5). There is however no significant correlation between total number of exercise and the level of adherence to HEP $(C=0.14$; $\mathrm{p}=0.88$ ) (Table 4).

The number of times per day agreed to carry out HEP by respondents showed that the majority $247(98.8 \%)$ performed the exercises 1-3 times daily (Table 4), though there was no significant relationship between number of times per day the exercise was performed and adherence to home exercise programme $(p=0.22)($ Table 5). The duration of exercise per session were grouped with majority $182(72.8 \%)$ performing the exercise for $10-15 \mathrm{minutes}$ (Table 4). There is however no significant relationship between the duration of exercise per session and adherence to home exercise programme $(C=0.08 ; p=0.92)$ (Table 4). Number of exercise repetition per session were also 
Correlates of Non-Adherence to Home Exercise Programmes in Patients with Low Back Pain

grouped from 1-15 with 5 intervals. Most respondents 121 (48.4) repeated the HEP 6-10 times per session (Table 4). However, there is no significant relationship between number of repetitions per session and adherence to home exercise programme in $\mathrm{LBP}(\mathrm{C}=-0.17 ; \mathrm{p}=0.85)$ (Table 4).

\subsection{COMPLIANCE WITH TREATMENT PROGRAMME}

The majority 94 (37.6\%) of respondents complied with the agreed number of times each day, 85 (34.0\%) respondents did HEP everyday but not the agreed number of times, 59 (23.6\%) respondents did the HEP occasionally but missed a few days, 7 (2.8\%) respondents did the HEP when feeling unwell and $2(0.8 \%)$ respondents did the HEP often but missed few days and same goes for respondents who never did HEP (Figure 2). Majority 218 (87.2\%) of respondents opined that the agreed amount of HEP was about right (Table 5). There was however no significant correlation between opinion about agreed amount of HEP and adherence to HEP $(\mathrm{C}=0.29 ; \mathrm{p}=0.77)$ (Table 5). The majority 178 (71.2\%) was of opinion that the amount of HEP they do at home was about right (Table 5).

A proportion of respondents identified between one and eighteen factors each that led to non-adherence while some left this section blank. The reasons most respondents, 89 (35.60\%) gave was: 'I feel too tired' (table 6). Other less commonly stated reasons are shown in the table 6. One hundred and fifty-six respondents (62.4\%) indicated the belief that HEP helped a great deal in reducing Low Back Pain (Table 7). The majority of respondents 231 (92.4\%) reported the physiotherapists clarified their doubt and answered questions whenever they asked (Table 7). However, there was no significant relationship between clarification of doubts and answering of questions and adherence to HEP (C= -0.35 ; $\mathrm{p}=0.63$ ) (Table 7).Two hundred and thirty two $(98.8 \%)$ respondents reported that physiotherapists' gave information about illness (Table 8).The majority $232(98.8 \%)$ justified the usefulness of physiotherapists advice (Table 8).

\subsection{INSTRUCTIONS FOR CARRYING OUT THE EXERCISES}

Home exercise programme were given verbally to most 247 (98.8\%) of respondents while $3(1.2 \%)$ were given in written form (Table 7). There was no significant relationship ( $\mathrm{C}=-0.35 ; \mathrm{p}=0.54)$ between way HEP was given and adherence to HEP (Table 7). Exercises of most respondents 238 (95.2\%) were supervised at the clinic. Follow-up exercise was received by 198 (79.2\%). One hundred and twenty-two (48.8\%) of respondents HEP were reviewed regularly (Table 8$)$. Chi -Square analysis showed statistically significant relationship $\left(X^{2}=127.85 ; p=0.00\right)$ between agreed amount prescribed at the clinic and the amount respondents actually do at home. Also, there was a significant relationship $\left(\mathrm{X}^{2}=30.312 ; \mathrm{p}=0.00\right)$ between perception of respondents about home exercise programme and amount respondents actually do at home (table 9).

\section{DISCUSSION}

One hundred percent response rate was obtained from this study unlike previous studies (Medina- Mirapeix et al 2009; Escolar- Reina et al, 2010). This may be due to the mode of distribution of the questionnaire which was by personal visitation to all the hospitals involved. The fact that there was no significant positive relationship between HEP and each of educational attainment, employment status, duration per session, opinion about agreed amount of HEP shows adherence to home exercise programme is neither influenced by how wealthy or educated an individual is. This showed that an individual's opinion about the home exercise programme or the number of times such a programme is performed per week would not affect his or her adherence. This finding disagrees with that of Hartigan et al, (2000) who concluded that educational attainment has positive influence on adherence to home exercise programme. It also disagrees with Sluijs et al, (1993) who reported non - compliance occurred most frequently among highly educated than non- educated.

In this study, it was observed that HEP had negative non-significant relationship with each of previous episodes of LBP, pain rating, total number of exercise given, times per day, repetition per session, and mode of translation of instruction for the programmes and patient's opinion about the exercise given. This showed that patient's previous experience of LBP or the instruction about exercise sessions and the way instruction was given to a patient about a home programme would not affect their adherence to it. These findings disagree with those of Sluijs and Knibbe (1991) and Shoo et al, (2004) who concluded that as pain frequency and intensity decreases, adherence to HEP also 
decreases and that during times of remission when symptoms are absent, patients lack relevant cues to continue with treatments. The difference between the findings of this work and those of the previous studies might be due to methodological differences. This study is a survey while the previous ones were prospective interventional studies. However, it can be deduced from this study that patient's previous experience of pain and exposure to home exercise programme would negatively affect their adherence to home exercise programme. This finding does not also agree with those of Chappell and Williams (2002) and Escolar- Reina et al (2010) who concluded that the higher the number of home exercise programme given to a patient, the less likelihood of adherence to them. However, in this study a negative non-significant relationship was observed between repetition and adherence. The difference between this study and that of the later is that their study was assessed at pre and post-intervention phases while this was a onetime survey of adherence. Martinet al, (2005) reported that even when information is communicated effectively and comprehension is initially high, much of what is conveyed during the medical visit is forgotten within moment of leaving the doctor's office. Jackson, (1992) also opined that optimal verbal communication does not exist, and the verbal communication between physicians and patients is often filled with medical terms and often impedes patients' comprehension and retention of information.

The finding that there was no significant relationship between previous experience of LBP and adherence to home programme however disagrees with Medina- Mirapiex et al, (2009) who reported that participation in HEP in previous episodes of LBP is a predictor of HEP. Also, the finding that level of pain did not significantly affect adherence to home progrmme disagrees with previous report by Sluijs et al, (1993) who concluded that level of pain is strongly associated with level of adherence. The finding of Escolar-Reina et al, (2010) showed that the more the number of home programmes, the less likelihood of adherence. However, in this study the highest number of home programme given to the majorities was ranged between one and three unlike in the later study where patients were given up to eight exercise programmes. This might have contributed to the non-significant relationship observed in this study.

The reasons given for non-adherence to home exercise programme by respondents in this study is consistent with previous study (Sluijs et al, 1993). Sluijs et al, 1993 further concluded that the barriers patients perceive, was the strongest factor in noncompliance to home exercise programme. The most frequent reported barrier was tiredness after a day's job as most of them were on paid employment. This have also been previously documented as barrier of adherence to home exercise programme (Sluijset al, 1993; Medina- Mirapiex et al, 2009).

The fact that patients' belief on the importance and helpfulness of physiotherapy HEP to the samelioration of their symptoms influence their adherence shows that adherence to home exercise programme is not determined by their perception of the importance of such programme to their health and alleviation of their symptoms. This finding disagrees with that of Chappell and Williams, (2002) on rates and reasons for non-adherence to home physiotherapy in paediatrics. There was also significant relationship between recommended amount of prescribed home exercise programme and the amount they actually do at home. Their noncompliance could be due to the fact that majorities were ranged between ages 59 and above and due to pathological and physiological effects of ageing which might have caused barriers in carrying out the prescribed exercises even though, they were given few number of home programmes. This corroborates Escolar-Reina et al, (2010) who earlier reported that when home exercise requires longer time of execution or includes exercises which are difficult to perform, adherence level will be low.

\section{CONCLUSION AND RECCOMMENDATION}

Based on the findings of this study, it is concluded that home exercise programme are frequently prescribed to patients with LBP in a range of 1-3 per session and at 6-10 repetitions in this environment and that patients with Low Back Pain in this environment agreed that home exercise programme helps a great deal and do it according to prescription but some perceived barriers affected their participation.

It is hereby recommended that home exercise programmes should be prescribed individually to fit into personal daily routine without interfering with normal lifestyle. Also, home exercise programme should be patients centered with regular review and evaluation to overcome identified barriers because it was seen from this study that the recommended amount of physiotherapy given at the hospital does not determine the amount patients actually perform at home. Considering the fact that a lot of barriers can influence adherence to home exercise programme in patients with low back pain, further studies may concentrate on given the home exercise programme individually and follow up to determine the rate of adherence throughout the period of prescribed exercise. 
Correlates of Non-Adherence to Home Exercise Programmes in Patients with Low Back Pain

Table 1: Sex, Age, Employment Status and First Contact with PT of Respondents

\begin{tabular}{|c|c|}
\hline & Frequency (\%) \\
\hline Sex: & $89(36)$ \\
\hline Female & $161(64)$ \\
\hline Age: & \\
\hline $20-39$ & $28(11)$ \\
\hline $40-59$ & $96(38)$ \\
\hline$>59$ & $126(51)$ \\
\hline Off work or sick leave: & \\
\hline Off work & $21(8.40)$ \\
\hline Sick leave & $12(4.80)$ \\
\hline On duty (not on leave) & $217(86.80)$ \\
\hline First contact with Physiotherapy: & \\
\hline Yes & $69(27.60)$ \\
\hline No & $181(72.40)$ \\
\hline
\end{tabular}

Table 2: Correlation between Adherence to HEP and Educational Attainments, Employment Status, HEP in the First Contact with Physiotherapist of respondents

\begin{tabular}{|c|c|c|c|}
\hline & Frequency (\%) & Coefficient & p-value \\
\hline Educational attainment: & & & \\
\hline No formal education & $49(19.60)$ & & \\
\hline Primary education & $33(13.20)$ & & \\
\hline Secondary education & $72(28.80)$ & 0.01 & 0.80 \\
\hline Tertiary education & $96(38.40)$ & & \\
\hline Paid employment: & & & \\
\hline Yes & $129(51.60)$ & & \\
\hline No & $121(49.20)$ & 0.00 & 0.99 \\
\hline Home exercise programme in first contact: & & & \\
\hline Yes & $40(16)$ & & \\
\hline No & $210(84)$ & -0.03 & 0.81 \\
\hline Extent of pain limitation from ADL: & & & \\
\hline Extremely & $69(27.60)$ & & \\
\hline Moderate & $67(26.80)$ & & \\
\hline Quite & $51(20.40)$ & & \\
\hline Slightly & $42(16.80)$ & & \\
\hline Not at all & $21(8.40)$ & & \\
\hline
\end{tabular}

Key: ADL= Activities of Daily Living; HEP= Home Exercise Programme 


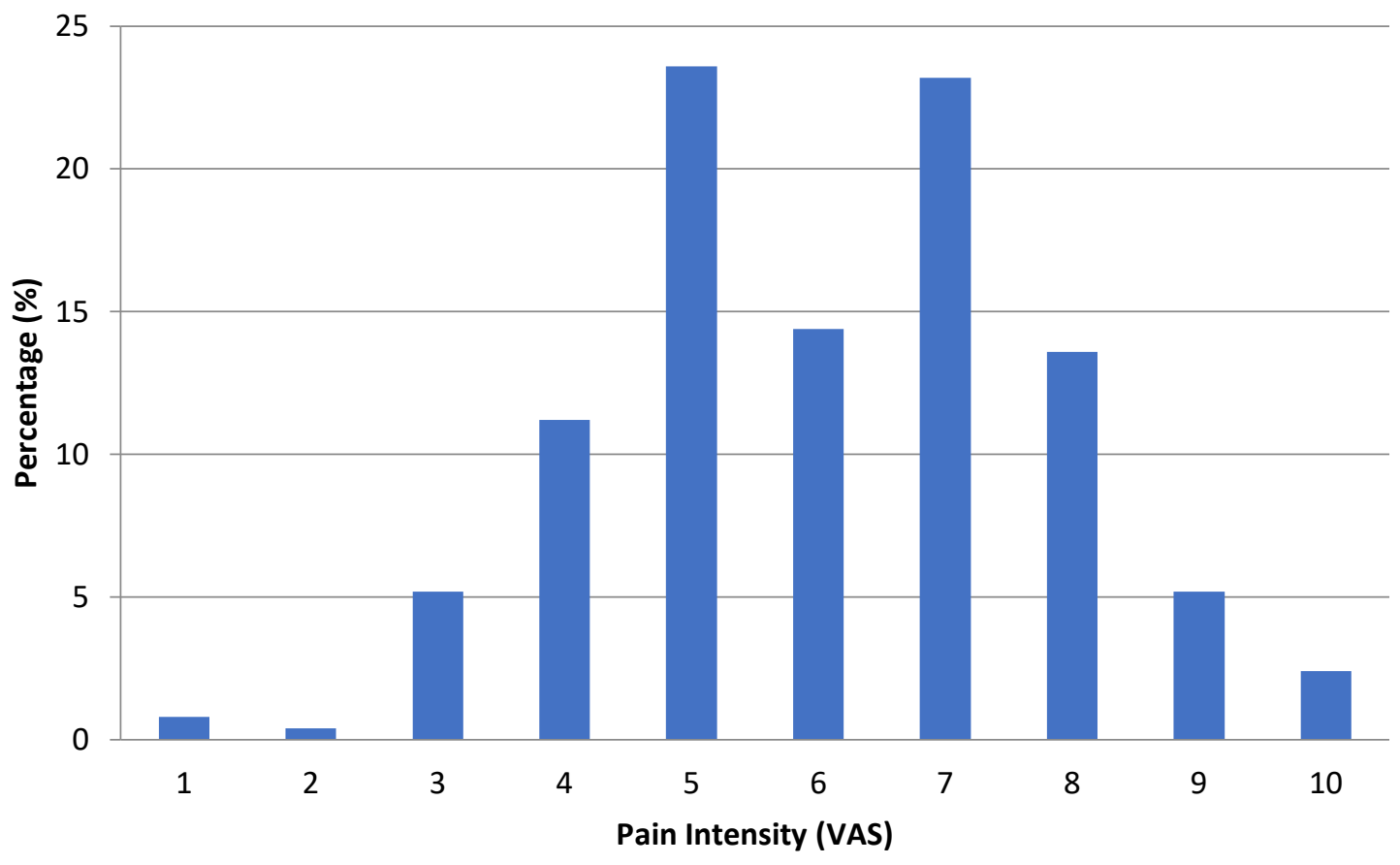

Figure 1: Pain Intensity (VAS) rating of the respondents

Table 3: Type of exercise and Number of Times per Week HEP was performed at Home (Respondents were allowed to choose more than one option in type of exercise)

Key: HEP= Home Exercise Programme

\begin{tabular}{|c|c|}
\hline & Frequency (\%) \\
\hline Type of exercise: & \\
\hline Forward bending & $54(21.60)$ \\
\hline Bending sideways & $50(20.00)$ \\
\hline Backward bending & $23(9.20)$ \\
\hline Modified press up & $86(34.40)$ \\
\hline Single knee to chest & $54(22.80)$ \\
\hline Double knee to chest & $83(33.20)$ \\
\hline
\end{tabular}

Table 4: Correlation between Adherence and Total no of exercise, Timesper Day,Duration per Session and Repetition of HEP

\begin{tabular}{|c|c|c|c|}
\hline & Frequency (\%) & Coefficient & p-value \\
\hline Total no of Exercise: & & & \\
\hline $1-3$ & $242(98.80)$ & & \\
\hline $4-5$ & $6(2.80)$ & & \\
\hline $5-6$ & $2(0.80)$ & -0.14 & 0.88 \\
\hline Times per Day: & & & \\
\hline $1-3$ & $247(98.80)$ & & \\
\hline $4-5$ & $2(0.80)$ & -0.56 & 0.22 \\
\hline$>6$ & $1(0.40)$ & & \\
\hline Times per Week: & & & \\
\hline Everyday & $218(87.20)$ & & \\
\hline Once & $3(12.00)$ & & \\
\hline Twice & $20(8.00)$ & & \\
\hline Thrice & $9(3.60)$ & & \\
\hline Duration per Session: & & & \\
\hline
\end{tabular}


Correlates of Non-Adherence to Home Exercise Programmes in Patients with Low Back Pain

\begin{tabular}{|c|c|c|c|}
\hline$<10$ mins & $68(27.20)$ & & \\
\hline $1-5 m i n s$ & $94(37.60)$ & & \\
\hline $6-10$ mins & $35(14.00)$ & 0.08 & 0.92 \\
\hline 11-15mins & $121(48.40)$ & & \\
\hline Repetition per session: & & & \\
\hline $1-5$ & $94(37.60)$ & & \\
\hline $6-10$ & $121(48.40)$ & & \\
\hline $11-15$ & $35(14.00)$ & -0.17 & 0.85 \\
\hline
\end{tabular}

Key: HEP= Home Exercise Programme

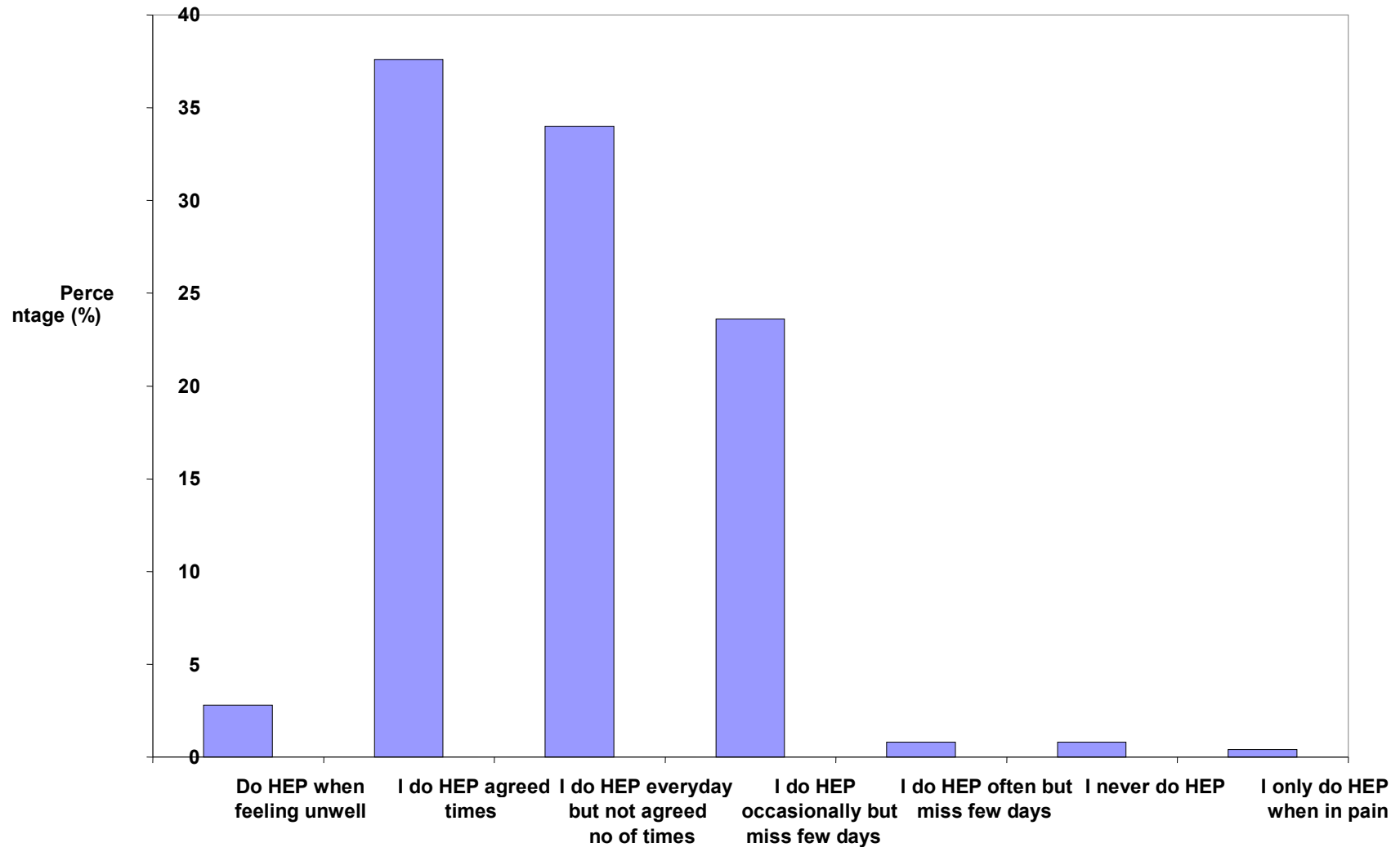

Figure 2: Compliance to HEP by Respondents

Table 5: Correlation betweeen Adherence to HEP and Opinion about Agreed Amount and Amount Respondents actually does at Home

\begin{tabular}{|c|c|c|c|}
\hline & Frequency (\%) & Coefficient & p-value \\
\hline Opinion about agreed amount: & & & \\
\hline It is about right & $218(87.20)$ & & \\
\hline It is too much & $2(0.80)$ & & \\
\hline It is not enough & $17(6.80)$ & 0.29 & 0.77 \\
\hline Don't know & $13(5.20)$ & & \\
\hline Amount done at home: & & & \\
\hline It is about right & $178(71.20)$ & & \\
\hline It is too much & $3(1.20)$ & & \\
\hline It is not enough & $60(24.00)$ & & \\
\hline Don't know & $9(3.60)$ & & \\
\hline
\end{tabular}


Table 6: Reasons Non- Adherence to Home Exercise Programme (Respondents were allowed to choose more than one option in this question)

\begin{tabular}{|c|c|}
\hline Reasons & Frequency (\%) \\
\hline I feel well without treatment & $17(6.80)$ \\
\hline It interferes with my social life & $11(4.40)$ \\
\hline I feel too tired & $89(35.60)$ \\
\hline I become too upset & $13(5.20)$ \\
\hline There isn't enough time & $33(13.20)$ \\
\hline I simply forget & $47(18.80)$ \\
\hline I have to rely on someone & $12(4.80)$ \\
\hline It interferes with my family life & $12(4.80)$ \\
\hline I can't be bothered & $11(4.40)$ \\
\hline I don't believe it does any good & $3(1.20)$ \\
\hline I have too many treatments to do & - \\
\hline It makes me feel worse & $9(3.60)$ \\
\hline I don't understand why I need it & - \\
\hline I do plenty exercises & $1(0.40)$ \\
\hline I don't know how to do it & - \\
\hline I resent doing it & - \\
\hline I find it embarrassing & $1(0.40)$ \\
\hline
\end{tabular}

Table 7: Correlation between Adherence to HEP and Perceived Benefit of HEP, Clarification of Doubts and Answering of Questions and given of information

\begin{tabular}{|c|c|c|c|}
\hline & Frequency (\%) & Coefficient & p-value \\
\hline Benefit of HEP: & & & \\
\hline Helps a great deal & $156(62.40)$ & & \\
\hline Helps a bit & $72(28.80)$ & & \\
\hline Makes no difference & $10(4.00)$ & & \\
\hline Makes me feel a little worse & $12(4.80)$ & & \\
\hline Clarification of doubts and answering of questions: & & & \\
\hline Yes & $231(92.40)$ & & \\
\hline No & $19(7.60)$ & -0.35 & 0.63 \\
\hline Ways of giving HEP: & & & \\
\hline Verbal & $247(98.80)$ & & \\
\hline Written & $3(1.20)$ & -0.35 & 0.54 \\
\hline
\end{tabular}

Table 8: Supervision, Follow-up, Regular Review of Exercise, Given of Informationand Usefulness of Advice by Respondents

\begin{tabular}{|c|c|c|}
\hline & YES & NO \\
\hline & Frequency (\%) & Frequency (\%) \\
\hline Supervision of Exercise: & $238(95.20)$ & $12(4.80)$ \\
\hline Follow-up Exercise: & $198(97.20)$ & $52(2.80)$ \\
\hline Regular Review: & $122(48.80)$ & $128(51.20)$ \\
\hline Information about Illness: & $232(92.80)$ & $18(7.20)$ \\
\hline Justification of Advice: & $232(92.80)$ & $18(7.20)$ \\
\hline
\end{tabular}

Table 9: Chi-Square Analysis for the Relationship between Opinion about Agreed Amount and Amount of Exercise Respondents Actually Does at Home

\begin{tabular}{|c|c|c|}
\hline & $\mathrm{X}^{2}$ & $\mathrm{p}$-value \\
\hline Agreed amount and amount done: & 127.85 & 0.00 \\
\hline Benefit of HEP and agreed amount of HEP: & 30.312 & 0.00 \\
\hline
\end{tabular}




\section{SOURCES OF FUNDING}

None.

\section{CONFLICT OF INTEREST}

None.

\section{ACKNOWLEDGMENT}

None.

\section{Questionnaire on Predictive Factors of Adherence to Frequency and Duration Components in Home Exercise programme for Low Back Pain}

\section{SECTION A: CHARACTERISTICS OF PATIENTS}

1. Gender

2. Age (as at last birthday in years) $\quad \square 18-39$

口Female

3. Highest education Level? $\square$ No formal education $\square$ Primary $\square$ Secondary $\square$ Tertiary

4. Are you presently working? 口Yes

$\square$ No

5. Are you presently off work or on sick leave due to pain? $\square$ Off work

$\square$ Sick Leave

\section{SECTION B: CHARACTERISTICS OF HOME EXERCISE PROGRAMME}
6. Have you had physiotherapy treatment before?
口Yes ‘nNo

7. Were you given home programme in your previous physiotherapy treatment?

口Yes $\quad$ aNo

8. If you put the pain you are experiencing on a scale, (' 0 ' being no pain and ' 10 ' worse pain), how will you rate?

(Tick the box that represents your experience)

$\square 0 \square 1 \square 2 \quad \square 3 \square 4 \quad \square 5 \square 6 \quad \square 7 \square 8 \quad \square 9 \square 10$

9. To what extent has the pain limited you from doing certain things you used to do before?

$\square$ Not at all slightly $\quad$ Q Quite Moderate $\quad$ Extremely

10. What type of exercises are you given? (Please tick the boxes that best describes)

口Forward bending abending sideways abackward bending

口modified press-up $\quad \square$ Single knee to chest in lying $\quad$ aDouble knee to chest in lying

11.What is the total no of exercises given to you? $\square 1-3 \quad \square$-5-6

12.How many times a day has it been agreed that you should do exercise program at home?

口1-3 $\quad \square \quad 4-5 \quad \square>6$

13.How many times per week has it been agreed that you should do home exercise programme?

口Everyday $\quad$ ance $\quad$ aTwice

14.How long per session are you supposed to perform your exercise at home?

$\square<10$ mins $\square 10-15$ mins

15.How many times/ repetitions are you supposed to perform each types of exercise in a session?

口1-5 times $\quad$ 66-10 times $\quad$ 11-15 times

\section{SECTION C: COMPLIANCE WITH TREATMENT PROGRAMME}

16.0ver the last four weeks which of the following statements best describes you? (Please tick the boxes that best describes)

$\square$ I do physiotherapy home programme the agreed number of times each day

$\square$ I do physiotherapy home programme everyday but not the agreed number of times

$\square$ I do physiotherapy home programme occasionally but miss a few days

$\square$ I do physiotherapy home programme often but miss a few days

$\square$ I do physiotherapy home programme whenfeeling unwell

$\square$ I never do physiotherapy home programme 

[6] Escolar-Reina P, Gascón-Cánovas J.J. ,Montilla-Herrador J., Jimeno-Serrano F.J, Collins S.M (2009). Predictive Factors of Adherence to Frequency and Duration Components in Home Exercise Programs for Neck and Low Back Pain: an Observational Study. BMC Musculoskeletal Disorders 10:155.

[7] Harreby M, Hesselsoe G, Kjer J, Neergaard K (1997): Low back pain and physical exercise in leisure time in 38-year-old men and women: a 25-year prospective cohort study of 640 school children. European Spine journal 6:181-186.

[8] Harris interactive (2010): Out - of - pocket cost are substantial barriers to prescription drug compliance. www.harrisinteractive.com, retrieved on July, 2010.

[9] Hartigan C, Rainville J, Sobel J B, Hipona M (2000): Long term exercise adherence after intensive rehabilitation for chronic low back pain. Medicine and Science in Sports and Exercise 32:551-557.

[10] Hartvigsen J, Frederiksen H, Christensen K (2004). Back and Neck Pain Exhibit Many Common Features in Old Age. A Population Based Study of 4,486 Danish Twins aged 70-102, Spine 29:576-580.

[11] Hayden JA, van Tulder MW, Malmivaara AV, Koes BW (2005): Meta-analysis: Exercise Therapy for Nonspecific Low Back Pain. Annals of Internal Medicine142:765-75.

[12] Hayden JA, van Tulder MW, Tomlinson G (2005): Systematic Review: Strategies for using Exercise Therapy to Improve Outcomes in Chronic Low Back Pain. Annalsof Internal Medicine 142:776-85.

[13] Jackson LD (1992): Information complexity and medical communication: the effects of technical language and amount of information in a medical message, Health Communication. 4:197-210.

[14] Journal of Physiotherapy, 31:60-6.

[15] Kay TM, Gross A, Goldsmith C, Santaguida PL, Hoving J, Bronfort G (2005): Exercises for Mechanical Neck Disorders. Cochrane Database Systematic Review: CD004250.

[16] Kolt GS, McEvoy JF (2003): Adherence to rehabilitation in patients with low back pain. Manipulative Therapy2003, 8:110-116.

[17] Louw QA, Morris LD, Grimmer-Sommers K (2007). The Prevalence of Low Back Pain in African: A systemic Review. BMC musculoskeletal Disorders 8:1474.

[18] Martin Descarreaux, DC, Martin C. Normand, DC, Laurencelle L., Dugas C., (2002): Evaluation of a specific home exercise program for low back pain, Journalof Manipulative Physiological Therapeutics 25:497-503.

[19] Martin LR, DiMatteo MR, Lepper HS (2001). Facilitation of patient involvement in care: development and validation of a scale. Behavioural Medicine. 27:111-120.

[20] Martin LR, Jahng KH, Golin CE (2003). Physician facilitation of patient involvement in care: correspondence between patient and observer reports. Behavioural Medicine. 28:159-64.

[21] Martin, L.R., Haskard, K.B., and Dimatteo, M.R. (2005). The challenge of patient adherence, Therapeutics and Clinical Risk Management 1.3 189-199.

[22] Medina-Mirapeix F, Escolar-Reina P, Gascón-Cánovas J.J ,Montilla-Herrador J, Jimeno-Serrano F.J, Collins S.M (2009). Predictive Factors of Adherence to Frequency and Duration Components in Home Exercise Programs for Neck and Low Back Pain: an Observational Study. BMC Musculoskeletal Disorders 10:155.

[23] Middleton A (2004). Chronic Low Back Pain: Patient Compliance with Physiotherapy Advice and Exercise, Perceived Barriers and Motivation.Physical Therapy Review 9:153-60.

[24] Moffett JK, Mclean S (2006): The Role of Physiotherapy in the Management of Non-Specific Back Pain and Neck Pain. Rheumatology 45:371-378.

[25] Peter Osmotherly, Nick Higginbotham (2004): Assessing Patient Intention to Perform a Home-Based Exercise Program for Back and Shoulder Pain: Physiotherapy Theory and Practice20.1: 57-71.

[26] Poitras, S., Blais, R., Swaine, B., and Rossignol, M. (2005). Research Report Management of Work-Related Low Back Pain: A Population-Based Survey Physical Therapy, 85: 1168-1181.

[27] Sarig-Bahat H (2003): Evidence for Exercise Therapy for Mechanical Neck Disorders. Manipulative Therapy 8:10-12.

[28] Schoo-Adrian MM, Morris-Meg E, Bui Q Minh (2004). Influence of home exercise performance, concurrent physical activities and analgesics on pain in people with osteoarthritis, New Zealand Journal Physiotherapy.

[29] Slade SC, Keating JL (2006). Trunk-Strengthening Exercises for Chronic Low Back Pain: A Systematic Review. Journal Manipulative Physiological Therapeutics 29:163-73. 
[30] Slade SC, Keating JL (2007). Unloaded Movement Facilitation Exercise Compared to No Exercise or Alternative Therapy on Outcomes for People with Non-Specific Chronic Low Back Pain: A Systematic Review. Journal of Manipulative Physiological Therapeutics 30:301-11.

[31] Sluijs E M, Kerssens J, van der Zee J and Myers L B (1998): Adherence to physiotherapy In: Myers L B and Midence K (Eds.): Adherence to treatment in medical conditions, 363- 382.Amsterdam.

[32] Sluijs EM, Kok GJ, van der Zee J (1993): Correlates of Exercise Compliance and Physical Therapy. Physical Therapy 73: 771-86.

[33] World Health Organization (2003): Adherence to Long-Term Therapies: Evidence for Action. Geneva: World Health Organization, ISBN 92-4-154599-2. 